\title{
BRCA1 tumor suppressor network: focusing on its tail
}

Bin Wang ${ }^{1,2}$

\begin{abstract}
Germline mutations of the BRCA1 tumor suppressor gene are a major cause of familial breast and ovarian cancer. BRCA1 plays critical roles in the DNA damage response that regulates activities of multiple repair and checkpoint pathways for maintaining genome stability. The BRCT domains of BRCA1 constitute a phospho-peptide binding domain recognizing a phospho-SPXF motif ( $S$, serine; $P$, proline; $\times$ varies; $F$, phenylalanine). The BRCT domains are frequently targeted by clinically important mutations and most of these mutations disrupt the binding surface of the BRCT domains to phosphorylated peptides. The BRCT domain and its capability to bind phosphorylated protein is required for the tumor suppressor function of BRCA1. Through its BRCT phospho-binding ability BRCA1 forms at least three mutually exclusive complexes by binding to phosphorylated proteins Abraxas, Bach1 and CTIP. The A, B and C complexes, at lease partially undertake BRCA1's role in mechanisms of cell cycle checkpoint and DNA repair that maintain genome stability, thus may play important roles in BRCA1's tumor suppressor function.
\end{abstract}

Germline mutations of the BRCA1 tumor suppressor gene are a major cause of familial breast and ovarian cancer [1,2]. BRCA1 plays critical roles in a number of diverse cellular processes that ensure genome integrity and the increase risk of breast and ovarian cancer caused by mutation of BRCA1 has been attributed to increased genomic instability. To safeguard genome, cells have evolved a defensive mechanism, called the DNA damage response (DDR), to coordinate multiple cellular responses including DNA repair, cell cycle checkpoint regulation, transcription, senescence or apoptosis etc., to counteract genotoxic stress [3-6]. BRCA1 appears to act as a central mediator of the cellular response to DNA damage that regulates the activities of multiple repair and checkpoint pathways [3,5,7-10]. BRCA1 is a substrate of the central DNA damage response kinases ATM/ATR that control the DDR. It is required for homology directed repair, a pathway that facilitates error-free repair of double-strand breaks (DSBs) and resolution of stalled DNA replication forks through homologous recombination (HR) [9-11] as well as postreplicative repair in response to UV damage [12]. Recently it is suggested that much of BRCA1's role in

\footnotetext{
Correspondence: bwang3@mdanderson.org

'Department of Genetics, The University of Texas M.D. Anderson Cancer

Center, 1515 Holcombe Blvd, Unit 1010, Houston, TX 77030, USA

Full list of author information is available at the end of the article
}

maintaining genome stability is accounted for by its role in maintaining heterochromatin integrity via $\mathrm{H} 2 \mathrm{~A}$ ubiquitination [13].

BRCA1 associates with multiple repair proteins and cell cycle regulators and such a capability to form multiple protein complexes contributes to its role in maintaining chromosome stability and tumor suppression (Figure 1). BRCA1 is a large protein of 1,863 amino acids. It contains two important domains at each end of the protein, a RING domain at the N-terminus and two BRCT domains at the $\mathrm{C}$-terminus. Many clinically important mutations of $B R C A 1$ gene frequently target these two domains. BRCA1 dimerizes with BARD1 through the RING domain present on each or the protein, forming an ubiquitin E3 ligase [14,15]. Earlier studies suggested that the E3 ligase activity of BRCA1 is essential for the DDR and tumor suppression function of BRCA1 [16-19]. Although a recent study using mouse embryonic stem cells and knock-in mouse models suggested that the E3 ligase activity of BRCA1 is not required for homology-directed repair of DSBs and tumor suppression $[20,21]$, the exact role of BRCA1 E3 ligase activity in DNA damage induced ubiquitin signaling and tumor suppression remains obscure. Another study examining mice carrying a pathogenic missense mutant of BRCA1 (C61G), which not only inactivates the E3 ligase activity but also disrupts BRCA1
C Biomed Central

(C) 2012 Wang; licensee BioMed Central Ltd. This is an Open Access article distributed under the terms of the Creative Commons Attribution License (http://creativecommons.org/licenses/by/2.0), which permits unrestricted use, distribution, and reproduction in any medium, provided the original work is properly cited. 


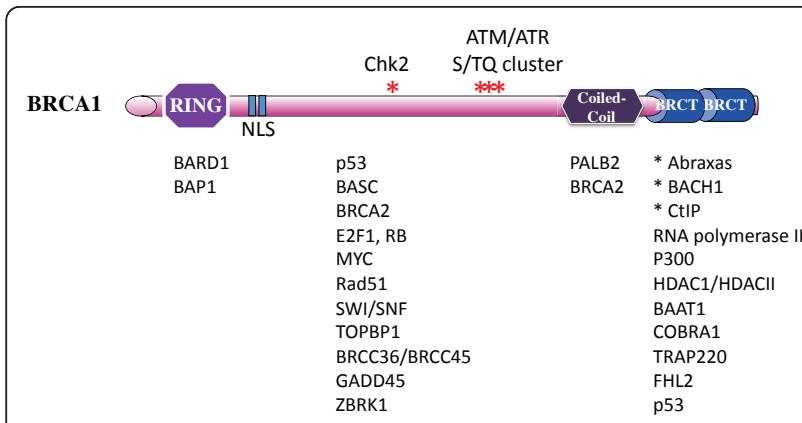

Figure 1 BRCA1 domains and interacting proteins. BRCA1 contains a RING domain at its N-terminus, two BRCT domains at the C-terminus and a coiled-coil domain upstream of BRCT domains. The interacting proteins are shown under the region of BRCA1 required for their association. BRCA1 forms an E3 ligase with BARD1 through its RING domain dimerizing with a RING domain containing protein BARD1. A ubiquitin hydrolase BAP1 also interacts with this region. The C-terminal BRCT domains form a phospho-binding module recognizing a phospho-SPxF motif. Abraxas, Bach1 and CtIP have been shown directly bind to BRCT domain through the phospho-SPXF motif. PALB2 binds to the coiled-coil domain of BRCA1 and bridges BRCA1-BRCA2 interaction. A number of other proteins have also been indicated binding to the $\mathrm{C}$-terminal region of BRCA1 or the central region of BRCA1. BRCA1 contains a S/TQ cluster that is phosphorylated by ATM/ATR at multiple sites. In addition, BRCA1 is also a substrate of Chk2

interaction with BARD1 [19], showed that this mutation, although compromised tumor suppression function of BRCA1, affects response to therapy possibly through residual activity of this mutant in DNA repair [22]. On the basis of in vitro assays, a number of ubiquitination substrates have been proposed for BRCA1/BARD1 E3 ligase, including histones, $\gamma$-tubulin, CTIP and BRCA1 itself, however, very few have been reported as substrates in vivo [23-25]. It has also been suggested that BRCA1/BARD1 is capable of interacting with various E2s directing either mono-ubiquitination, or polyubiquitination with different linkages, such as lysine 63 (K63)-, lysine 48 (K48)- or lysine 6 (K6)- linkages [26,27]. A recent study suggested that the BRCA1 mediated histone ubiquitination is required for its role in suppressing satellite DNA repeats transcription in the heterchromatin region and maintenance of genome stability [13]. However it is still not clear whether BRCA1's role in maintaining histone $\mathrm{H} 2 \mathrm{~A}$ ubiquitination at heterochromatin satellite DNA repeats is important for tumorigenesis.

\section{BRCA1 forms three different complexes through its C-terminus BRCT domains}

The BRCT domains of BRCA1 constitute a phosphopeptide binding domain recognizing a phospho-SPxF motif $(S$, serine; $P$, proline; $\times$ varies; $F$, phenylalanine) [28-30]. The fact that the BRCT domains are frequently targeted by many clinically important mutations and most of these mutations disrupt the binding surface of the BRCT domains to phosphorylated peptides indicates that they are integral for BRCA1's tumor suppressor function [31]. A recent study of mice carrying a BRCT mutant of BRCA1 that is defective in recognition of phosphorylated proteins and mice carrying an E3 ligase defective mutant of BRCA1 indicates that BRCT phosphoprotein recognition but not the E3 ligase activity is required for BRCA1 tumor suppression [20,21].

Although multiple proteins have been suggested to associate with the C-terminus of BRCA1 protein, so far, three proteins Abraxas (also known as Abra1, CCDC98), Bach1 (also known as Brip1, FancJ) and CtIP (also known as RBBP8) have been shown directly interact with the BRCT domains of BRCA1 through the phospho-SPxF motif in a phosphorylation-dependent manner forming mutually exclusive complexes, which were thus named as the A, B and C complexes of BRCA1 $[29,32,33]$ (Figure 2). Although it remains largely unknown how these complexes transmit BRCA1 signaling, it appears that these three complexes of BRCA1 are involved in multiple functions of BRCA1 and thus may be essential for BRCA1's tumor suppressor function. This review will thus focus on a summary of the formation and functions of these three BRCA1-BRCT associated complexes.

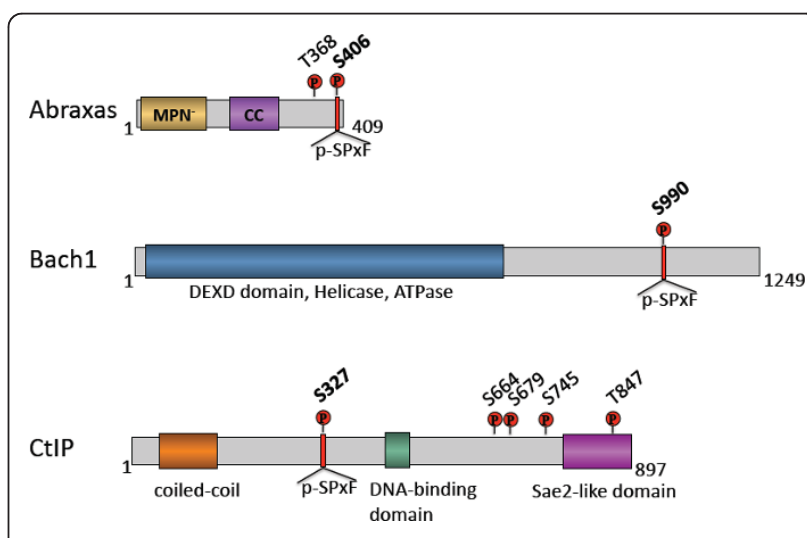

Figure 2 Three proteins Abraxas, Bach 1 and CtIP contain pSPXF motif that binds to the BRCT domains of BRCA1.

Schematic diagram showing protein domains of three BRCA1-BRCT associated proteins. The phospho-Ser-Pro-X-Phe (p-SPxF) motif is illustrated on each protein. In addition, Abraxas contains a MPNdomain that binds to $\mathrm{Ub}$ and a coiled-coil domain that interacts with BRCC36. Abraxas also contains a ATM/ATR phosphorylation site (T368). Bach1 contains a helicase domain. CtIP contains a coiled-coil domain at its $\mathrm{N}$-terminus that is responsible for dimerization of the protein. T847 of CtIP is phosphorylated by CDK and the phosphorylation is required for its ability to promote DNA end resection. CtIP is also phosphorylated by ATM/ATR at S644, S679 and S745. The 509-557 region of CTIP binds to DNA directly in vitro and is required for recruitment to DSB in cells [34] 


\section{BRCA1-A complex is a deubiquitinating (DUB) complex}

The BRCA1 A complex contains at least five different components: Rap80, Abraxas, NBA1 (also known as MERIT40), BRE (also known as BRCC45) and BRCC36 [32,35-41]. Abraxas interacts with the BRCT domains of BRCA1 through a phospho-serine group (p-S406) at the C-terminus of Abraxas, and mediates the interaction of the A complex with BRCA1. In fact, Abraxas appears to serve as a central organizing adaptor protein that not only mediates the interaction of the A complex and BRCA1 but also bridges the interaction of each member of the BRCA1-A complex [32,35,42]. It is worth noting that NBA1 and BRE interaction is critical for maintaining the integrity of the BRCA1-A complex [43]. NBA1 interacts with BRE through a $\mathrm{C}$-terminal conserved PxxR ( $P$, proline; $x$ varies; $R$, arginine) motif of the NBA1 protein and a $C$-terminal UEV domain of the BRE protein. Knockdown of NBA1 or BRE leads to decreased levels of components of the complex and compromised BRCA1-A complex function [43].

Modification of proteins by the covalent attachment of ubiquitin (Ub) to the lysine residue of a target protein is a key regulatory mechanism of many cellular processes including DNA damage response $[44,45]$. Ubiquitination occurs through a three-step process involving Ub-activating enzyme (E1), Ub-conjugating (E2) and Ub-ligating (E3) enzyme. The types of Ub modifications that can form are diverse. Monoubiquitin occurs as a single Ub molecule is attached. Alternatively, a polyubiquitin (polyUb) chain is formed when one of the seven lysine residues side chains within ubiquitin is linked to the Cterminal glycine of another ubiquitin. The best-characterized linkages to date utilize ubiquitin lysine 48 (K48) and lysine 63 (K63). K48-linked polyUb predominantly targets proteins for proteasomal degradation, whereas K63-linked polyUb more often regulates protein function, subcellular localization, or protein-protein interactions. K63 polyUb chain linkage plays important roles in the recruitment of repair factors in the DDR [3].

Protein ubiquitination is a reversible process, and it has become increasingly obvious that Ub deconjugation plays important roles in regulating the Ub-dependent pathways [46-49]. Deubiquitinating enzymes (DUBs) catalyze the removal of $\mathrm{Ub}$ from Ub-conjugated substrate proteins. DUBs also function in processing of Ub precursors and Ub adducts. BRCC36 in the BRCA1 A complex is a deubiquitinating enzyme (DUB). BRCC36 was initially identified as a BRCA1 associated protein that contains a $\mathrm{MPN}^{+} /$JAMM domain indicative of a metalloprotease activity [50]. It is later found indeed having a deubiquitinating activity specifically toward K63-polyUb linkages [38,51].
One unique feature of the BRCA1 A complex is that multiple ubiquitin binding motifs exist in the BRCA1 A complex. Four members of the BRCA1 A complex, Rap80, Abra1, BRE, and BRCC36, possess polyUb chain binding capability while only the UIM domains of Rap80 display Lys63-linkage specific polyUb binding [35]. BRCC36, Abraxas and BRE, which contains MPN ${ }^{+}$, $\mathrm{MPN}^{-}$and $\mathrm{UBC}$ domain respectively, appear to prefer binding to longer polyUb chains with no apparent linkage specificity [35]. Thus, it is likely that the BRCA1 A complex is assembled in a specific manner to facilitate the DUB activity of BRCC36. Interestingly, the BRCA1 A complex bears similarities with the lid of the 19S proteasome regulatory complex [35]. The $19 \mathrm{~S}$ proteasome lid $[52,53]$ cleaves ubiquitin from substrates and facilitates the entry of substrates into the catalytic proteasome core for degradation [54-56]. In the lid, Rpn11 contains an active $\mathrm{MPN}^{+} / \mathrm{JAMM}$ motif that posesses a DUB activity for substrate deubiquitination, while Rpn8 contains an enzymatically inactive $\mathrm{MPN}^{-}$domain. Similarly, the BRCA1 A complex contains a $\mathrm{MPN}^{+} / \mathrm{MPN}^{-}$ pair present in BRCC36 $\left(\mathrm{MPN}^{+}\right)$and Abraxas $\left(\mathrm{MPN}^{-}\right)$ proteins. These two proteins dimerizes with each other through a coiled-coil domain on each of the protein. In addition, while a component of the $19 \mathrm{~S}$ proteasome lid, Rpn10/S5a, contains UIM domains and a VWA domain [57], in the BRCA1-A complex, Rap80 possesses UIM domains at its $\mathrm{N}$-terminus and NBA1 contains a VWA domain. Although the significance of this similarity is not clear, it is likely the BRCA1 A complex is assembled to facilitate the cleavage of ubiquitin from substrates. Indeed, it was shown that interactions of BRCC36 with other components of the complex are critical for the optimum DUB activity of BRCC36 $[37,58]$. In the BRCA1 A complex, the UIM domains of Rap80 bind specifically to K63-linked polyUb chains while the deubiquitinating enzyme BRCC36 displays an specificity toward these chains $[35,38,40,59]$. Therefore, the BRCA1 A complex appears to be a DUB complex processing K63-linked polyUb signals during the DDR.

\section{BRCA1-A complex mediates DNA damage induced ubiquitin signaling for recruitment of BRCA1 to DSBs}

Ubiquitination occurs at the double strand breaks (DSBs) in a central DNA damage kinases ATM/ATR dependent manner $[3,4,6]$. Upon DNA damage, a damage induced ATM/ATR phosphorylation on Ser139 of histone $\mathrm{H} 2 \mathrm{AX}$ directly recruits MDC1 through MDC1's BRCT domains. MDC1 itself is a substrate of ATM/ATR, and its phosphorylation leads to the recruitment of an ubiquitin E3 ligase/E2 conjugase, RNF8/ UBC13, to damage sites [42,60-62]. Another chromatin- 
associated ubiquitin E3 ligase RNF168 was also identified working with Ubc13 to amplify the RNF8-dependent polyubiquitin (polyUb) signal that is required for BRCA1 recruitment $[63,64]$. The RNF8/RNF168 dependent ubiquitination is further facilitated by yet another E3 ligase HERC2 [65,66]. The subsequent ubiquitination events on the damaged chromatin create docking sites for DNA damage repair proteins such as 53BP1 and BRCA1 $[3,4,6]$. In a parallel pathway, H2AX ubiquitaination by PRC1 also contributes to BRCA1 recruitment [67]. So far, histones H2A and H2AX have been indicated as substrates of these E3 ligases although yet unidentified substrates at DSBs may also likely exist. A recent report indicates that $M D C 1$ is likely to be another substrate with a lysine residue in the MDC BRCT domain ubiquitinated in a Ubc13-dependent manner for interaction and optimum recruitment of Rap80 [68]. Unlike the canonical Lys48-linked polyUb that targets the substrate protein for proteasomal degradation, RNF8/RNF168-dependent ubiquitination around DNA damage sites appears to generate K63-linked polyUb for recruitment of DNA repair proteins [3,60-64].

The BRCA1 A complex accumulates to DSBs in a RNF8/RNF168 dependent manner. The two UIM domains of Rap 80 and their capability to bind K63polyUb are required for accumulation of Rap 80 and other components of the BRCA1-A complex to sites of damage $[32,38,40,59]$. The BRCA1 A complex plays an important role in recruiting BRCA1 to DNA damage sites. Down regulation of each component of this complex compromised the recruitment of BRCA1 to DNA damage sites, leading to increased cell sensitivity to ionizing radiation (IR) and inability of cells to arrest the cell cycle as well as compromised homology recombinationdependent repair in response to DNA damage $[32,35,36,38,40,69,70]$. The exact role of the BRCA1-A complex in DSB repair and BRCA1 signaling in tumor suppression is still not clear. It is suggested that BRCC36 antagonizes RNF8-Ubc13 dependent ubiquitination such that inhibition of BRCC36 leads to an increased accumulation of RNF8/Ubc13-dependent ubiquitination at DSBs [71]. In addition, it has been suggested that BRCC36 and BRE might be involved in regulating the E3 ligase activity of BRCA1/BARD1 [50]. Nevertheless, the fact that both the BRCA1/BARD1 E3 ligase and the BRCC36 deubiquitinating enzyme are present at DNA damage sites raises the possibility that additional ubiquitin modifications might be necessary to enhance or maintain the ubiquitin signaling events initiated by the RNF8/RNF168 ligases. Functional analyses of the BRCA1-A complex should allow us to further dissect the role of BRCA1 in the DDR and tumor suppression.

\section{An independent DUB complex formed by Abraxas paralog ABRO1}

Abraxas protein has a paralog ABRO1 (Abraxas brother 1 ), which is $39 \%$ identical to Abraxas at the N-terminal region including both a $\mathrm{MPN}^{-}$domain and a coiled-coil domain yet lacking the phospho-SPxF motif at its C-terminus $[32,37,43,58,72]$. Interestingly, although ABRO1 does not interact with Abraxas, it assembles a DUB complex in a similar manner as Abraxas with several components of the BRCA1 A complex including BRCC36, NBA1 and BRE. While Abraxas mainly localizes in the nucleus mediating the interaction of A complex with BRCA1, ABRO1 is mainly localized in the cytoplasm. Because it lacks the BRCA1 interacting motif, ABRO1 does not interact with BRCA1. The ABRO1 complex (also known as BRISC complex) contains at least ABRO1, BRE, NBA1, and BRCC36. ABRO1 and BRCC36 interaction is required for the DUB activity of BRCC36 in vitro [72]. While Rap80 localizes in the nucleus and is only present in the Abraxas/BRCA1-A complex, BRCC36, BRE, and NBA1 are expressed both in nucleus and cytoplasm and are present in both complexes. The ABRO1/BRISC complex appears to associate with the COP9 signalosome [51]. It was also suggested that ABRO1/BRISC deficiency enhances formation of the BRCA1-Rap80 interaction and increased BRCA1 levels at the DNA damage sites $[37,58]$. However, the exact role of the ABRO1/BRISC complex needs further investigation to be understood.

\section{BRCA1-A complex and Cancer}

A screen of non-BRCA1 or BRCA2 mutant familiar breast tumors identified a in-frame deletion of residue 81 glutamic acid of Rap80 that displays reduced ubiquitin binding and compromised ability to recruit A complex and BRCA1 to DSBs [73]. Recently, two genome wide association studies (GWAS) implicated that common genetic variants in NBA1 may predispose women to serous ovarian or hormone negative breast cancer $[74,75]$. In addition, BRCC36 gene is abnormally expressed in several breast cancer cell lines and a subset of sporadic breast tumors [50]. Together, it indicates that BRCA1-A complex may play an important role in breast tumor development.

\section{BRCA1-B complex is required for replication stress induced checkpoint control and DNA interstrand crosslink repair}

The BRCA1-B complex is formed through phosphorylated S990 of Bach1 binding to BRCA1 BRCT [29]. Bach1 Ser990 is phosphorylated by CDK in a cell cycledependent manner $[29,76]$. Earlier, it was found that Bach1 is required for progression through $S$ phase [77] 
and is required for cell cycle checkpoint that accumulates cells at G2 phase (G2 accumulation) after DNA damage $[29,76]$. In fact, Bach1 interacts with TopBP1 forming a complex that is required for replication stress induced checkpoint [78]. Both TopBP1 and Bach1 are required for the extension of single stranded DNA regions and RPA loading following replication stress [78].

Bach1 was first identified as a DEAH helicase domain containing protein that binds to the BRCT domains of BRCA1 [79]. It was then discovered to be a member of the Fanconi anemia protein, FancJ [80-83]. Fanconi anemia (FA) is a rare genetic disorder associated with various developmental defects and a high incidence of malignancies [84-86]. The FA patients' cells are extremely sensitive to agents that induce DNA interstrand crosslinks [84-86] indicating that Bach1 plays a role in the DNA interstrand crosslink repair.

In vitro studies suggest that Bach1 is a DNA dependent ATPase, which unwinds DNA in a 5' to 3' direction [87]. Furthermore, Bach1 preferentially binds and unwinds DNA substrates that mimic an intermediate step in homologous recombination [88]. Indeed, Bach1 is required for DNA repair through HR. Expression of a helicase dead mutant of FancJ in cells results in the accumulation of unrepaired DNA breaks and decreased HR [79]. In addition, depletion of Bach1 by siRNAs was also shown to compromise HR $[82,86]$. Bach1 enzyme activity as well as the BRCA1-FancJ interaction is essential for DNA repair, checkpoint activation and tumor suppression $[29,89,90]$.

Multiple germline mutations that disrupt Bach1 enzyme activity or BRCA1 association have been identified in breast cancer indicating Bach1 is a tumor suppressor [89]. Recently a frame shift mutations in the Bach1 gene that greatly affect the risk of invasive ovarian cancer has also been identified in ovarian cancer [91].

\section{BRCA1-C complex is required for DNA end resection}

The BRCA1-C complex consists of CtIP and the MRN (Mre11/Rad50/Nbs1) complex. BRCA1 forms such a complex with CtIP and MRN in a cell cycle-dependent manner during $S$ and $G 2$ phase of the cell cycle through the BRCT domains of BRCA1 binding to phosphorylated S327, a CDK phosphorylation site of CtIP in a phospho-SPxF motif $[76,92]$. CtIP is a functional homolog of yeast Sae 2 and is required for DNA end resection at the initial step of homologous recombination (HR) dependent DSB repair [93,94]. CtIP promotes DNA end resection by interacting and stimulating the nuclease activity of the MRN complex. The complex formation of BRCA1-CtIP-MRN is important for facilitating DSB resection to generate single-stranded DNA that is needed for HR-mediated DSB repair [92].

Similar to Sae2, of which CDK-dependent phosphorylation promotes resection activity, CDK phosphorylation of CtIP at T847 is required for DSB resection and subsequent $\mathrm{HR}$ in the $\mathrm{S}$ and G2 phase $[95,96]$. Recruitment of CtIP to DSB requires MRN [34,92,97]. Both of the N-terminus and C-terminus of CtIP have been indicated to interact with the NBS1 subunit of the MRN [92,94,97]. CtIP recruitment to damage sites also requires ATM kinase activity [34]. It was shown that S664/S745 phosphorylated by ATM is required for CtIP recruitment to DNA damage sites and DSB end resection [98]. It was also suggested that following DNA damage the ubiquitination of CtIP by BRCA1 is critical for the recruitment of CtIP towards a chromatin fraction [25]. In addition, like Sae2, CtIP is acetylated, and deacetylation of CtIP by SIRT6 promotes DNA end resection $[99,100]$.

CtIP is also implicated a role in microhomology-directed alternative nonhomolgous end-joing pathway (altNHEJ) and the CtIP-mediated alt-NHEJ has a primary role in chromosome translocation formation and class switch recombination $[101,102]$. A study in chicken DT40 cells analyzing a mutant of CTIP that fails to associate with BRCA1 suggested that BRCA1-CtIP interaction is required for HR-mediated repair during S-G2 phase progression but involved in microhomologymediated NHEJ in a BRCA1-independent manner in G1 phase of the cell cycle [103]. Yet another study in chicken DT40 cells suggested that CtIP interaction with BRCA1 is not required for HR-mediated repair [104]. While the discrepancy needs to be further analyzed, the biological significance of the complex formed between BRCA1 and CtIP has not yet been fully studied in mammalian cells.

CtIP is an essential gene in mammalian cells, inactivation of which is embryonic lethal in mice [105]. However, haploid insufficiency of CtIP predisposes mice to multiple types of tumor indicating CtIP is a tumor suppressor [105]. Consistent with its role in the DDR, a recent report showed that mutations of CtIP that generates a dominant-negative C-terminus truncated form of CtIP protein causes Seckel and Jawad Syndromes which is a genome instability disorder and associated with cancer predisposition [106].

\section{Functions of BRCA1 A, B and C complexes in DNA DSB repair}

Eukaryotic cells possess at least three distinct mechanisms for DSB repair including NHEJ (non-homologous end joining), SSA (single-strand annealing) and HR (homologous recombination) [4,107]. NHEJ involves the 
direct re-ligation of the broken DNA ends and can be error prone if terminal bases are removed prior to ligation. SSA utilizes short stretches of sequence homology flanking the break following DSB resection for annealing resulting in deletion of intervening sequences and loss of genetic information. In contrast to the error-prone repair mechanisms NHEJ and SSA, HR accurately repair DSBs in S-phase and G2-phase cells. HR is initiated by nucleolytic processing of the DSB end to generate 3' ssDNA (single-stranded DNA) overhangs. In the presence of ATP, Rad51 forms a helical nucleoprotein filament on ssDNA that is needed for invasion of the ssDNA into a donor sister chromatid or homologous chromosome to form a joint molecule for homologous recombination. The BRCA1-C complex plays a critical role in the initial resection of DSB end. This is followed by long-range resection dependent on the DNA exonuclease Exo I and the helicase Bloom syndrome protein (BLM), which provides the ssDNA substrates for HR [107]. The BRCA1-B complex also plays a role in HR, yet its specific mechanism remains unclear. BRCA1 associates with BRCA2 through PALB2 [108-110]. BRCA2 promotes the loading of $\operatorname{Rad} 51$ to ssDNA for efficient HR repair [111]. Intriguingly it is still not clear how the BRCA1-A complex is involved in HR. Although an earlier report indicated BRCA1 A complex promotes HR since HR is compromised in BRCA1-A complex deficient cells [32], more recent reports suggest that BRCA1-A complex supresses HR such that with depletion of Rap80 or Abraxas, both the B and C complexes assembly at DSB was increased and HR was hyperactivated [112,113]. While it awaits further study for a better understanding of how each of the complex contribute to HR, it is clear that BRCA1 BRCT is critical for $\mathrm{HR}$ at least partially through forming the $\mathrm{A}, \mathrm{B}$ and $\mathrm{C}$ complexes.

\section{Functions of BRCA1 A, B and C complexes in DNA damage induced checkpoint regulation}

Studies on A, B and C complexes of BRCA1 indicate that these complexes carry out functions of BRCA1 in cell cycle checkpoint control. Both $\mathrm{A}$ and $\mathrm{C}$ complexes of BRCA1 have been indicated critical for G2-M checkpoint control in response to IR to ensure that entry into mitosis is transiently inhibited to avoid aberrant chromosome segregation $[32,35,36,38,40,69,70]$. Interestingly knocking down any components of the A complex such as Rap80, Abraxas, NBA1, BRE, BRCC36 or the $\mathrm{C}$ complex component CtIP, the phenotype of G2-M checkpoint deficiency is much milder compared to cells depleted of BRCA1 indicating that only partial function of BRCA1 in G2-M checkpoint control is defective when individual complex was deficient $[32,35,36,38,40,69,70,76]$. In fact, synthetic knockdown of both Abraxas and CtIP proteins led to a G2-M checkpoint defect comparable to BRCA1-deficient cells [32] indicating that BRCA1 function in G2-M checkpoint control might involve both of the $\mathrm{A}$ and $\mathrm{C}$ complexes. While the B complex does not appear to be involved in the transient G2-M checkpoint control [76], it is required for G2-accumulation checkpoint that is also observed for BRCA1-deficient cells $[29,76,114]$. The mechanism of the G2-accumulation checkpoint is still not well defined. In addition, the $B$ complex of BRCA1 is also involved in the replication checkpoint control in response to replication stress [78]. Since BRCA1 appears to be required for multiple checkpoints regulation including the replication checkpoint and G2-M checkpoint control, different BRCA1 associated complexes may only carry out partial of its function in distinctive checkpoints.

\section{Concluding remarks}

The BRCT domain of BRCA1 has been indicated important for cell cycle checkpoint, HR and tumor suppression [3,5,7-10]. The recent mouse model expressing a BRCT mutant of BRCA1 (S1598F, corresponding to human BRCA1 S1655F) incapable of binding to phospho-peptides in place of the wild type allele of BRCA1 failed to suppress breast tumor development further confirms that the BRCT domain and its capability to bind phosphorylated protein is required for the tumor suppressor function of BRCA1 [21]. Through its BRCT phospho-binding ability BRCA1 forms at least three mutually exclusive complexes by binding to phosphorylated proteins Abraxas, Bach1 and CTIP. The A, B and $\mathrm{C}$ complexes, at lease partially undertake BRCA1's role in mechanisms of cell cycle checkpoint and DNA repair that maintain genome stability (Figure 3), although it remains largely unknown how the formation of these complexes are regulated or coordinated. Many other proteins have also been reported binding to the BRCT domains of BRCA1 although it is not clear whether these proteins bind with a direct interaction $[115,116]$. It is likely additional BRCT associated complexes exist carrying additional roles of BRCA1 in a number of diverse cellular processes in maintaining genome stability and tumor suppression.

Although it is evident that BRCT domains are essential for BRCA1's tumor suppression, it remains unclear how the BRCT domain associated complexes are coordinated with signaling complexes that associate through other regions of the BRCA1 protein. Together, BRCA1 emerges to be a central mediator of the cellular 


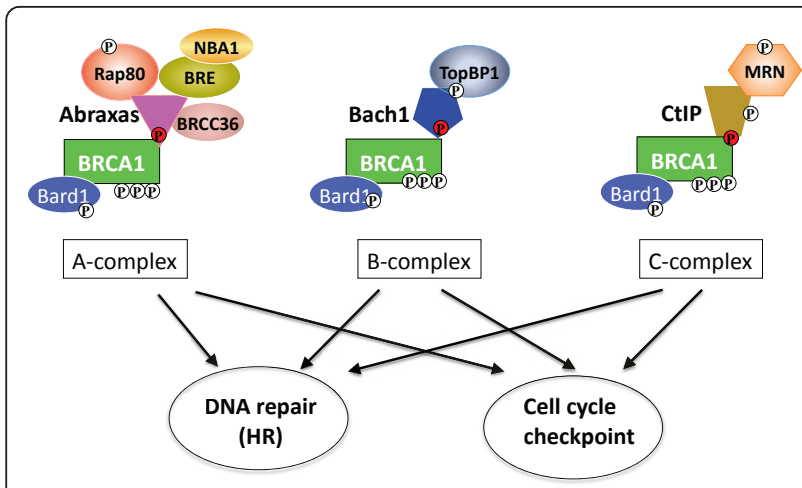

Figure 3 A, B and C complex of BRCA1 contributes to BRCA1's role in cell cycle checkpoint regulation and DNA repair. In addition to forming C-terminal associated complexes, BRCA1 contains a coiled-coil domain upstream of BRCT domain, which interacts with a coiled-coil domain at the N-terminus of PALB2. PALB2 associates with BRCA2 thus bridging the interaction of BRCA1 and BRCA2 [117-119]. The N-terminus RING domain, in addition to dimerizing with BARD1 forming an E3 ligase, this region is also reported to interact with a ubiquitin hydrolase BAP1 $[120,121]$. Previous studies suggested that the central region of BRCA1 is also reported to interact with multiple proteins either directly or indirectly $[115,116]$. In addition, BRCA1 contains a S/TQ cluster that is phosphorylated by ATM/ATR at multiple sites and the phosphorylation is critical for BRCA1's role in cell cycle checkpoints regulation in the DDR [5]. BRCA1 has also been reported to be a substrate of Chk2 at $\mathrm{S988}$ [122].

mechanism that maintains genome stability that brings together multiple signaling complexes in response to DNA damage, yet much remains to be learned to fully appreciate the role of BRCA1 as a tumor suppressor.

\section{Acknowledgements}

This work was supported by grants from National Cancer Institute (CA155025), Mel Klein Family Fund, Sidney Kimmel Scholar Award, a pilot project grant from Center of Cancer Genetics and Genomics, and the Startup Fund from MD Anderson Cancer Center.

\section{Author details}

'Department of Genetics, The University of Texas M.D. Anderson Cancer Center, 1515 Holcombe Blvd, Unit 1010, Houston, TX 77030, USA. ${ }^{2}$ Genes and Development Program, The University of Texas Graduate School of Biomedical Sciences, Houston, TX 77030, USA.

\section{Authors' contributions}

BW is the sole author of this manuscript.

\section{Competing interests}

The authors declare that they have no competing interests.

Received: 7 December 2011 Accepted: 27 February 2012 Published: 27 February 2012

\section{References}

1. Narod SA, Foulkes WD: BRCA1 and BRCA2: 1994 and beyond. Nat Rev Cancer 2004, 4(9):665-676.

2. Venkitaraman AR: Cancer susceptibility and the functions of BRCA1 and BRCA2. Cell 2002, 108(2):171-182.
3. Harper JW, Elledge SJ: The DNA damage response: ten years after. Mol Cell 2007, 28(5):739-745.

4. Ciccia A, Elledge SJ: The DNA damage response: making it safe to play with knives. Mol Cell 2010, 40(2):179-204.

5. Zhou BB, Elledge SJ: The DNA damage response: putting checkpoints in perspective. Nature 2000, 408(6811):433-439.

6. Polo SE, Jackson SP: Dynamics of DNA damage response proteins at DNA breaks: a focus on protein modifications. Genes Dev 2011, 25(5):409-433.

7. Deng CX: BRCA1: cell cycle checkpoint, genetic instability, DNA damage response and cancer evolution. Nucleic Acids Res 2006, 34(5):1416-1426.

8. Huen MS, Sy SM, Chen J: BRCA1 and its toolbox for the maintenance of genome integrity. Nat Rev Mol Cell Biol 2010, 11(2):138-148.

9. Nagaraju G, Scully R: Minding the gap: the underground functions of BRCA1 and BRCA2 at stalled replication forks. DNA Repair (Amst) 2007 6(7):1018-1031

10. Powell SN, Kachnic LA: Roles of BRCA1 and BRCA2 in homologous recombination, DNA replication fidelity and the cellular response to ionizing radiation. Oncogene 2003, 22(37):5784-5791.

11. Moynahan ME, Chiu JW, Koller BH, Jasin M: Brca1 controls homologydirected DNA repair. Mol Cell 1999, 4(4):511-518.

12. Pathania S, Nguyen J, Hill SJ, Scully R, Adelmant GO, Marto JA, Feunteun J, Livingston DM: BRCA1 Is Required for Postreplication Repair after UVInduced DNA Damage. Mol Cell 2011, 44(2):235-251.

13. Zhu Q, Pao GM, Huynh AM, Suh H, Tonnu N, Nederlof PM, Gage FH, Verma IM: BRCA1 tumour suppression occurs via heterochromatinmediated silencing. Nature 2011, 477(7363):179-184

14. Wu-Baer F, Lagrazon K, Yuan W, Baer R: The BRCA1/BARD1 heterodimer assembles polyubiquitin chains through an unconventional linkage involving lysine residue K6 of ubiquitin. J Biol Chem 2003, 278(37):34743-34746.

15. Hashizume R, Fukuda M, Maeda I, Nishikawa H, Oyake D, Yabuki Y, Ogata $H$ Ohta T: The RING heterodimer BRCA1-BARD1 is a ubiquitin ligase inactivated by a breast cancer-derived mutation. J Biol Chem 2001, 276(18):14537-14540.

16. Morris JR, Solomon E: BRCA1: BARD1 induces the formation of conjugated ubiquitin structures, dependent on K6 of ubiquitin, in cells during DNA replication and repair. Hum Mol Genet 2004, 13(8):807-817.

17. Polanowska J, Martin JS, Garcia-Muse T, Petalcorin Ml, Boulton SJ: A conserved pathway to activate BRCA1-dependent ubiquitylation at DNA damage sites. EMBO J 2006, 25(10):2178-2188.

18. Morris JR, Pangon L, Boutell C, Katagiri T, Keep NH, Solomon E: Genetic analysis of BRCA1 ubiquitin ligase activity and its relationship to breast cancer susceptibility. Hum Mol Genet 2006, 15(4):599-606.

19. Ruffner H, Joazeiro CA, Hemmati D, Hunter T, Verma IM: Cancerpredisposing mutations within the RING domain of BRCA1: loss of ubiquitin protein ligase activity and protection from radiation hypersensitivity. Proc Natl Acad Sci USA 2001, 98(9):5134-5139.

20. Reid LJ, Shakya R, Modi AP, Lokshin M, Cheng JT, Jasin M, Baer R, Ludwig T: E3 ligase activity of BRCA1 is not essential for mammalian cell viability or homology-directed repair of double-strand DNA breaks. Proc Natl Acad Sci USA 2008, 105(52):20876-20881

21. Shakya R, Reid L, Reczek CR, Cole F, Egli D, Lin CS, deRooij DG, Hirsch S, Ravi K, Hicks JB, et al: BRCA1 tumor suppression depends on BRCT phosphoprotein binding, but not its E3 ligase activity. Science 2011, 334(6055):525-528.

22. Drost $R$, Bouwman $P$, Rottenberg $S$, Boon U, Schut E, Klarenbeek S, Klijn C, van der Heijden I, van der Gulden H, Wientjens E, et al: BRCA1 RING function is essential for tumor suppression but dispensable for therapy resistance. Cancer Cell 2011, 20(6):797-809.

23. Wu W, Koike A, Takeshita T, Ohta T: The ubiquitin E3 ligase activity of BRCA1 and its biological functions. Cell Div 2008, 3:1.

24. Boulton SJ: BRCA1-mediated ubiquitylation. Cell Cycle 2006, 5(14):1481-1486.

25. Yu X, Fu S, Lai M, Baer R, Chen J: BRCA1 ubiquitinates its phosphorylation-dependent binding partner CtIP. Genes Dev 2006 20(13):1721-1726.

26. Christensen DE, Brzovic PS, Klevit RE: E2-BRCA1 RING interactions dictate synthesis of mono- or specific polyubiquitin chain linkages. Nat Struct Mol Biol 2007, 14(10):941-948

27. Christensen DE, Klevit RE: Dynamic interactions of proteins in complex networks: identifying the complete set of interacting E2s for functional 
investigation of E3-dependent protein ubiquitination. FEBS / 2009, 276(19):5381-5389

28. Manke IA, Lowery DM, Nguyen A, Yaffe MB: BRCT repeats as phosphopeptide-binding modules involved in protein targeting. Science 2003, 302(5645):636-639.

29. Yu X, Chini CC, He M, Mer G, Chen J: The BRCT domain is a phosphoprotein binding domain. Science 2003, 302(5645):639-642.

30. Rodriguez M, Yu X, Chen J, Songyang Z: Phosphopeptide binding specificities of BRCA1 COOH-terminal (BRCT) domains. J Biol Chem 2003, 278(52):52914-52918

31. Glover JN: Insights into the molecular basis of human hereditary breast cancer from studies of the BRCA1 BRCT domain. Fam Cancer 2006, 5(1):89-93.

32. Wang B, Matsuoka S, Ballif BA, Zhang D, Smogorzewska A, Gygi SP, Elledge SJ: Abraxas and RAP80 form a BRCA1 protein complex required for the DNA damage response. Science 2007, 316(5828):1194-1198.

33. Greenberg RA, Sobhian B, Pathania S, Cantor SB, Nakatani Y, Livingston DM: Multifactorial contributions to an acute DNA damage response by BRCA1/BARD1-containing complexes. Genes Dev 2006, 20(1):34-46.

34. You Z, Shi LZ, Zhu Q, Wu P, Zhang YW, Basilio A, Tonnu N, Verma IM, Berns MW, Hunter T: CtIP links DNA double-strand break sensing to resection. Mol Cell 2009, 36(6):954-969.

35. Wang B, Hurov K, Hofmann $K$, Elledge SJ: NBA1, a new player in the Brca1 A complex, is required for DNA damage resistance and checkpoint control. Genes Dev 2009, 23(6):729-739.

36. Feng L, Huang J, Chen J: MERIT40 facilitates BRCA1 localization and DNA damage repair. Genes Dev 2009, 23(6):719-728.

37. Patterson-Fortin J, Shao G, Bretscher H, Messick TE, Greenberg RA: Differential regulation of JAMM domain deubiquitinating enzyme activity within the RAP80 complex. J Biol Chem 2010, 285(40):30971-30981

38. Sobhian B, Shao G, Lilli DR, Culhane AC, Moreau LA, Xia B, Livingston DM, Greenberg RA: RAP80 targets BRCA1 to specific ubiquitin structures at DNA damage sites. Science 2007, 316(5828):1198-1202.

39. Kim H, Huang J, Chen J: CCDC98 is a BRCA1-BRCT domain-binding protein involved in the DNA damage response. Nat Struct Mol Biol 2007, 14(8):710-715

40. Kim H, Chen J, Yu X: Ubiquitin-binding protein RAP80 mediates BRCA1dependent DNA damage response. Science 2007, 316(5828):1202-1205.

41. Liu Z, Wu J, Yu X: CCDC98 targets BRCA1 to DNA damage sites. Nat Struct Mol Biol 2007, 14(8):716-720.

42. Wang B, Elledge SJ: Ubc13/Rnf8 ubiquitin ligases control foci formation of the Rap80/Abraxas/Brca1/Brcc36 complex in response to DNA damage. Proc Natl Acad Sci USA 2007, 104(52):20759-20763.

43. Hu X, Kim JA, Castillo A, Huang M, Liu J, Wang B: NBA1/MERIT40 and BRE interaction is required for the integrity of two distinct deubiquitinating enzyme BRCC36-containing complexes. J Biol Chem 2011، 286(13):11734-11745.

44. Haglund K, Dikic I: Ubiquitylation and cell signaling. EMBO J 2005, 24(19):3353-3359.

45. Sun L, Chen ZJ: The novel functions of ubiquitination in signaling. Curr Opin Cell Biol 2004, 16(2):119-126.

46. Love KR, Catic A, Schlieker C, Ploegh HL: Mechanisms, biology and inhibitors of deubiquitinating enzymes. Nat Chem Biol 2007, 3(11):697-705

47. Song L, Rape M: Reverse the curse-the role of deubiquitination in cell cycle control. Curr Opin Cell Biol 2008, 20(2):156-163.

48. Ventii $\mathrm{KH}$, Wilkinson KD: Protein partners of deubiquitinating enzymes. Biochem J 2008, 414(2):161-175

49. Reyes-Turcu FE, Ventii KH, Wilkinson KD: Regulation and cellular roles of ubiquitin-specific deubiquitinating enzymes. Annu Rev Biochem 2009, 78:363-397.

50. Dong Y, Hakimi MA, Chen X, Kumaraswamy E, Cooch NS, Godwin AK, Shiekhattar R: Regulation of BRCC, a holoenzyme complex containing BRCA1 and BRCA2, by a signalosome-like subunit and its role in DNA repair. Mol Cell 2003, 12(5):1087-1099

51. Cooper EM, Cutcliffe C, Kristiansen TZ, Pandey A, Pickart CM, Cohen RE: K63-specific deubiquitination by two JAMM/MPN+ complexes: BRISCassociated Brcc36 and proteasomal Poh1. EMBO J 2009, 28(6):621-631.
52. Lam YA, Lawson TG, Velayutham M, Zweier JL, Pickart CM: A proteasomal ATPase subunit recognizes the polyubiquitin degradation signal. Nature 2002, 416(6882):763-767.

53. Glickman MH, Rubin DM, Coux O, Wefes I, Pfeifer G, Cjeka Z, Baumeister W, Fried VA, Finley D: A subcomplex of the proteasome regulatory particle required for ubiquitin-conjugate degradation and related to the COP9signalosome and elF3. Cell 1998, 94(5):615-623.

54. Yao T, Cohen RE: A cryptic protease couples deubiquitination and degradation by the proteasome. Nature 2002, 419(6905):403-407.

55. Verma R, Aravind L, Oania R, McDonald WH, Yates JR, Koonin EV, Deshaies RJ: Role of Rpn11 metalloprotease in deubiquitination and degradation by the $26 \mathrm{~S}$ proteasome. Science 2002, 298(5593):611-615.

56. Maytal-Kivity V, Reis N, Hofmann K, Glickman MH: MPN+, a putative catalytic motif found in a subset of MPN domain proteins from eukaryotes and prokaryotes, is critical for Rpn11 function. BMC Biochem 2002, 3:28.

57. Elsasser S, Finley D: Delivery of ubiquitinated substrates to proteinunfolding machines. Nat Cell Biol 2005, 7(8):742-749.

58. Feng L, Wang J, Chen J: The Lys63-specific deubiquitinating enzyme BRCC36 is regulated by two scaffold proteins localizing in different subcellular compartments. J Biol Chem 2010, 285(40):30982-30988.

59. Yan J, Kim YS, Yang XP, Albers M, Koegl M, Jetten AM: Ubiquitininteraction motifs of RAP80 are critical in its regulation of estrogen receptor \{alpha\}. Nucleic Acids Res 2007, 277(35):32379-32388.

60. Mailand N, Bekker-Jensen S, Faustrup H, Melander F, Bartek J, Lukas C, Lukas J: RNF8 ubiquitylates histones at DNA double-strand breaks and promotes assembly of repair proteins. Cell 2007, 131(5):887-900.

61. Kolas NK, Chapman JR, Nakada S, Ylanko J, Chahwan R, Sweeney FD, Panier S, Mendez M, Wildenhain J, Thomson TM, et al: Orchestration of the DNA-damage response by the RNF8 ubiquitin ligase. Science 2007, 318(5856):1637-1640.

62. Huen MS, Grant R, Manke I, Minn K, Yu X, Yaffe MB, Chen J: RNF8 transduces the DNA-damage signal via histone ubiquitylation and checkpoint protein assembly. Cell 2007, 131(5):901-914.

63. Doil C, Mailand N, Bekker-Jensen S, Menard P, Larsen DH, Pepperkok R, Ellenberg J, Panier S, Durocher D, Bartek J, et al: RNF168 binds and amplifies ubiquitin conjugates on damaged chromosomes to allow accumulation of repair proteins. Cell 2009, 136(3):435-446.

64. Stewart GS, Panier S, Townsend K, Al-Hakim AK, Kolas NK, Miller ES, Nakada S, Ylanko J, Olivarius S, Mendez M, et al: The RIDDLE syndrome protein mediates a ubiquitin-dependent signaling cascade at sites of DNA damage. Cell 2009, 136(3):420-434.

65. Wu W, Sato K, Koike A, Nishikawa H, Koizumi H, Venkitaraman AR, Ohta T: HERC2 is an E3 ligase that targets BRCA1 for degradation. Cancer Res 2010, 70(15):6384-6392.

66. Bekker-Jensen S, Rendtlew Danielsen J, Fugger K, Gromova I, Nerstedt A, Lukas C, Bartek J, Lukas J, Mailand N: HERC2 coordinates ubiquitindependent assembly of DNA repair factors on damaged chromosomes. Nat Cell Biol 2010, 12(1):80-86, sup pp 81-12.

67. Ismail IH, Andrin C, McDonald D, Hendzel MJ: BMI1-mediated histone ubiquitylation promotes DNA double-strand break repair. J Cell Biol 2010, 191(1):45-60.

68. Strauss C, Halevy T, Macarov M, Argaman L, Goldberg M: MDC1 is ubiquitylated on its tandem BRCT domain and directly binds RAP80 in a UBC13-dependent manner. DNA Repair (Amst) 2011, 10(8):806-814.

69. Shao G, Patterson-Fortin J, Messick TE, Feng D, Shanbhag N, Wang Y, Greenberg RA: MERIT40 controls BRCA1-Rap80 complex integrity and recruitment to DNA double-strand breaks. Genes Dev 2009, 23(6):740-754.

70. Chen X, Arciero CA, Wang C, Broccoli D, Godwin AK: BRCC36 is essential for ionizing radiation-induced BRCA1 phosphorylation and nuclear foci formation. Cancer Res 2006, 66(10):5039-5046.

71. Shao G, Lilli DR, Patterson-Fortin J, Coleman KA, Morrissey DE, Greenberg RA: The Rap80-BRCC36 de-ubiquitinating enzyme complex antagonizes RNF8-Ubc13-dependent ubiquitination events at DNA double strand breaks. Proc Natl Acad Sci USA 2009, 106(9):3166-3171.

72. Cooper EM, Boeke JD, Cohen RE: Specificity of the BRISC deubiquitinating enzyme is not due to selective binding to Lys63-linked polyubiquitin. J Biol Chem 2010, 285(14):10344-10352.

73. Nikkila J, Coleman KA, Morrissey D, Pylkas K, Erkko H, Messick TE, Karppinen SM, Amelina A, Winqvist R, Greenberg RA: Familial breast cancer 
screening reveals an alteration in the RAP80 UIM domain that impairs DNA damage response function. Oncogene 2009, 28(16):1843-1852.

74. Antoniou AC, Wang X, Fredericksen ZS, McGuffog L, Tarrell R, Sinilnikova OM, Healey S, Morrison J, Kartsonaki C, Lesnick T, et al: A locus on 19p13 modifies risk of breast cancer in BRCA1 mutation carriers and is associated with hormone receptor-negative breast cancer in the general population. Nat Genet 2011, 42(10):885-892.

75. Bolton KL, Tyrer J, Song H, Ramus SJ, Notaridou M, Jones C, Sher T, GentryMaharaj A, Wozniak E, Tsai YY, et al: Common variants at 19p13 are associated with susceptibility to ovarian cancer. Nat Genet 2011, 42(10):880-884.

76. Yu X, Chen J: DNA damage-induced cell cycle checkpoint control requires CtIP, a phosphorylation-dependent binding partner of BRCA1 Cterminal domains. Mol Cell Biol 2004, 24(21):9478-9486.

77. Kumaraswamy E, Shiekhattar R: Activation of BRCA1/BRCA2-associated helicase $\mathrm{BACH} 1$ is required for timely progression through $\mathrm{S}$ phase. Mol Cell Biol 2007, 27(19):6733-6741.

78. Gong Z, Kim JE, Leung CC, Glover JN, Chen J: BACH1/FANCJ acts with TopBP1 and participates early in DNA replication checkpoint control. Mol Cell 2010, 37(3):438-446.

79. Cantor SB, Bell DW, Ganesan S, Kass EM, Drapkin R, Grossman S, Wahrer DC, Sgroi DC, Lane WS, Haber DA, et al: BACH1, a novel helicase-like protein, interacts directly with BRCA1 and contributes to its DNA repair function. Cell 2001, 105(1):149-160

80. Levitus M, Waisfisz Q, Godthelp BC, de Vries Y, Hussain S, Wiegant WW, Elghalbzouri-Maghrani E, Steltenpool J, Rooimans MA, Pals G, et al: The DNA helicase BRIP1 is defective in Fanconi anemia complementation group J. Nat Genet 2005, 37(9):934-935.

81. Levran O, Attwooll C, Henry RT, Milton KL, Neveling K, Rio P, Batish SD, Kalb R, Velleuer E, Barral S, et al: The BRCA1-interacting helicase BRIP1 is deficient in Fanconi anemia. Nat Genet 2005, 37(9):931-933.

82. Litman $R$, Peng $M$, Jin Z, Zhang F, Zhang J, Powell S, Andreassen PR, Cantor SB: BACH1 is critical for homologous recombination and appears to be the Fanconi anemia gene product FANCJ. Cancer Cell 2005, 8(3):255-265.

83. Bridge WL, Vandenberg CJ, Franklin RJ, Hiom K: The BRIP1 helicase functions independently of BRCA1 in the Fanconi anemia pathway for DNA crosslink repair. Nat Genet 2005, 37(9):953-957.

84. Moldovan GL, D'Andrea AD: How the fanconi anemia pathway guards the genome. Annu Rev Genet 2009, 43:223-249.

85. D'Andrea AD: The Fanconi Anemia/BRCA signaling pathway: disruption in cisplatin-sensitive ovarian cancers. Cell Cycle 2003, 2(4):290-292.

86. Wang W: Emergence of a DNA-damage response network consisting of Fanconi anaemia and BRCA proteins. Nat Rev Genet 2007, 8(10):735-748.

87. Cantor S, Drapkin R, Zhang F, Lin Y, Han J, Pamidi S, Livingston DM: The BRCA1-associated protein BACH1 is a DNA helicase targeted by clinically relevant inactivating mutations. Proc Natl Acad Sci USA 2004, 101(8):2357-2362.

88. Gupta R, Sharma S, Sommers JA, Jin Z, Cantor SB, Brosh RM Jr: Analysis of the DNA substrate specificity of the human BACH1 helicase associated with breast cancer. J Biol Chem 2005, 280(27):25450-25460

89. Cantor SB, Guillemette S: Hereditary breast cancer and the BRCA1associated FANCJ/BACH1/BRIP1. Future Oncol 2011, 7(2):253-261.

90. Xie J, Litman R, Wang S, Peng M, Guillemette S, Rooney T, Cantor SB: Targeting the FANCJ-BRCA1 interaction promotes a switch from recombination to poleta-dependent bypass. Oncogene 2010, 29(17):2499-2508.

91. Rafnar T, Gudbjartsson DF, Sulem P, Jonasdottir A, Sigurdsson A, Besenbacher S, Lundin P, Stacey SN, Gudmundsson J, Magnusson OT, et al: Mutations in BRIP1 confer high risk of ovarian cancer. Nat Genet 2011, 43(11):1104-1107.

92. Chen L, Nievera CJ, Lee AY, Wu X: Cell cycle-dependent complex formation of BRCA1.CtIP.MRN is important for DNA double-strand break repair. J Biol Chem 2008, 283(12):7713-7720.

93. Limbo O, Chahwan C, Yamada Y, de Bruin RA, Wittenberg C, Russell P: Ctp1 is a cell-cycle-regulated protein that functions with Mre11 complex to control double-strand break repair by homologous recombination. $\mathrm{Mol}$ Cell 2007, 28(1):134-146.

94. Sartori AA, Lukas C, Coates J, Mistrik M, Fu S, Bartek J, Baer R, Lukas J, Jackson SP: Human CtIP promotes DNA end resection. Nature 2007, 450(7169):509-514.
95. Huertas P, Cortes-Ledesma F, Sartori AA, Aguilera A, Jackson SP: CDK targets Sae2 to control DNA-end resection and homologous recombination. Nature 2008, 455(7213):689-692.

96. Huertas P, Jackson SP: Human CtIP mediates cell cycle control of DNA end resection and double strand break repair. J Biol Chem 2009, 284(14):9558-9565.

97. Yuan J, Chen J: $\mathrm{N}$ terminus of CtIP is critical for homologous recombination-mediated double-strand break repair. J Biol Chem 2009, 284(46):31746-31752

98. Shibata A, Conrad S, Birraux J, Geuting V, Barton O, Ismail A, Kakarougkas A, Meek K, Taucher-Scholz G, Lobrich M, et al: Factors determining DNA double-strand break repair pathway choice in G2 phase. EMBO J 2011, 30(6):1079-1092.

99. Robert T, Vanoli F, Chiolo I, Shubassi G, Bernstein KA, Rothstein R, Botrugno OA, Parazzoli D, Oldani A, Minucci S, et al: HDACs link the DNA damage response, processing of double-strand breaks and autophagy. Nature 2011, 471(7336):74-79.

100. Kaidi A, Weinert BT, Choudhary C, Jackson SP: Human SIRT6 promotes DNA end resection through CtIP deacetylation. Science 2010, 329(5997):1348-1353.

101. Zhang Y, Jasin M: An essential role for CtIP in chromosomal translocation formation through an alternative end-joining pathway. Nat Struct Mol Biol 2011, 18(1):80-84.

102. Lee-Theilen M, Matthews AJ, Kelly D, Zheng S, Chaudhuri J: CtIP promotes microhomology-mediated alternative end joining during class-switch recombination. Nat Struct Mol Biol 2011, 18(1):75-79.

103. Yun MH, Hiom K: CtIP-BRCA1 modulates the choice of DNA doublestrand-break repair pathway throughout the cell cycle. Nature 2009, 459(7245):460-463.

104. Nakamura K, Kogame T, Oshiumi H, Shinohara A, Sumitomo Y, Agama K, Pommier Y, Tsutsui KM, Tsutsui K, Hartsuiker E, et al: Collaborative action of Brca1 and CtIP in elimination of covalent modifications from doublestrand breaks to facilitate subsequent break repair. PLoS Genet 2010, 6(1): e1000828.

105. Chen PL, Liu F, Cai S, Lin X, Li A, Chen Y, Gu B, Lee EY, Lee WH: Inactivation of CtIP leads to early embryonic lethality mediated by G1 restraint and to tumorigenesis by haploid insufficiency. Mol Cell Biol 2005, 25(9):3535-3542.

106. Qvist P, Huertas P, Jimeno S, Nyegaard M, Hassan MJ, Jackson SP, Borglum AD: CtIP Mutations Cause Seckel and Jawad Syndromes. PLoS Genet 2011, 7(10):e1002310

107. Mimitou EP, Symington LS: DNA end resection: many nucleases make light work. DNA Repair (Amst) 2009, 8(9):983-995.

108. Xia B, Sheng Q, Nakanishi K, Ohashi A, Wu J, Christ N, Liu X, Jasin M, Couch FJ, Livingston DM: Control of BRCA2 cellular and clinical functions by a nuclear partner, PALB2. Mol Cell 2006, 22(6):719-729.

109. Scully R, Chen J, Plug A, Xiao Y, Weaver D, Feunteun J, Ashley T, Livingston DM: Association of BRCA1 with Rad51 in mitotic and meiotic cells. Cell 1997, 88(2):265-275.

110. Chen J, Silver DP, Walpita D, Cantor SB, Gazdar AF, Tomlinson G, Couch FJ, Weber BL, Ashley T, Livingston DM, et al: Stable interaction between the products of the BRCA1 and BRCA2 tumor suppressor genes in mitotic and meiotic cells. Mol Cell 1998, 2(3):317-328.

111. Thorslund T, West SC: BRCA2: a universal recombinase regulator. Oncogene 2007, 26(56):7720-7730.

112. Hu Y, Scully R, Sobhian B, Xie A, Shestakova E, Livingston DM: RAP80directed tuning of BRCA1 homologous recombination function at ionizing radiation-induced nuclear foci. Genes Dev 2011, 25(7):685-700.

113. Coleman KA, Greenberg RA: The BRCA1-RAP80 complex regulates DNA repair mechanism utilization by restricting end resection. $J$ Biol Chem 2011, 286(15):13669-13680.

114. Xu B, Kim S, Kastan MB: Involvement of Brca1 in S-phase and G(2)-phase checkpoints after ionizing irradiation. Mol Cell Biol 2001, 21(10):3445-3450.

115. Deng CX, Brodie SG: Roles of BRCA1 and its interacting proteins. BioEssays 2000, 22(8):728-737.

116. Boulton SJ: Cellular functions of the BRCA tumour-suppressor proteins. Biochem Soc Trans 2006, 34(Pt 5):633-645.

117. Sy SM, Huen MS, Zhu Y, Chen J: PALB2 regulates recombinational repair through chromatin association and oligomerization. J Biol Chem 2009, 284(27):18302-18310. 
118. Zhang F, Ma J, Wu J, Ye L, Cai H, Xia B, Yu X: PALB2 links BRCA1 and BRCA2 in the DNA-damage response. Curr Biol 2009, 19(6):524-529.

119. Zhang F, Fan Q, Ren K, Andreassen PR: PALB2 functionally connects the breast cancer susceptibility proteins BRCA1 and BRCA2. Mol Cancer Res 2009, 7(7):1110-1118

120. Jensen DE, Proctor M, Marquis ST, Gardner HP, Ha SI, Chodosh LA, Ishov AM, Tommerup N, Vissing H, Sekido Y, et al: BAP1: a novel ubiquitin hydrolase which binds to the BRCA1 RING finger and enhances BRCA1mediated cell growth suppression. Oncogene 1998, 16(9):1097-1112.

121. Fang $Y, F u D$, Shen $X Z$ : The potential role of ubiquitin c-terminal hydrolases in oncogenesis. Biochim Biophys Acta 1806, 1:1-6.

122. Lee JS, Collins KM, Brown AL, Lee CH, Chung JH: hCds1-mediated phosphorylation of BRCA1 regulates the DNA damage response. Nature 2000, 404(6774):201-204.

doi:10.1186/2045-3701-2-6

Cite this article as: Wang: BRCA1 tumor suppressor network: focusing on its tail. Cell \& Bioscience 2012 2:6.

\section{Submit your next manuscript to BioMed Central} and take full advantage of:

- Convenient online submission

- Thorough peer review

- No space constraints or color figure charges

- Immediate publication on acceptance

- Inclusion in PubMed, CAS, Scopus and Google Scholar

- Research which is freely available for redistribution

Submit your manuscript at www.biomedcentral.com/submit 